\title{
Using Old Maps to Analyse Land Use/Cover Change in Water Reservoir Area
}

\author{
Darina Kratochvilova ${ }^{\text {a }}$, , Jiri Cajthaml ${ }^{\mathrm{a}}$ \\ ${ }^{a}$ Czech Technical University in Prague, Faculty of Civil Engineering, Department of Geomatics, Thakurova 7, Prague, Czech \\ Republic, darina.kratochvilova@fsv.cvut.cz, Jiri Cajthaml, jiri.cajthaml@fsv.cvut.cz \\ * Corresponding author
}

Keywords: Old maps, Land use/cover change (LUCC), Historical landscape, GIS, Water dam

\begin{abstract}
:
The construction of the dam represents a major impact on the landscape and has a significant effect on land use/cover changes around the newly created reservoir. Flooding of part of the original river valley often leads to the extinction of historically valuable areas and buildings. By comparing relevant old and current maps covering the area of interest, we can obtain spatial data that can be processed with the help of geoinformation technologies, and thus obtain information about land use/cover changes in the water reservoir area.
\end{abstract}

The subject of our research was land use/cover changes and development surrounding the Orlík waterworks. The Orlík dam is located in the middle part of the Vltava River, the longest and probably the most famous river in the Czech Republic. The construction of the dam in the 1950s created a water reservoir with an area of over 2700 ha, which significantly transformed the landscape of the original Vltava valley. The dam was named after the castle, which once stood above the deep valley of the Vltava and is now located a few meters above the water reservoir. With its volume of retained water, it is the largest reservoir in the Czech Republic and its area is the second largest. The Orlík waterworks represents the most important part of the so-called Vltava cascade. The Vltava Cascade is a set of 9 dams built on the upper and middle part of the Vltava River, mainly in the second half of the 20th century, for the purpose of generating electricity, regulating flow and defending against floods. Side benefits included the creation of new recreational sites.

Land use/cover changes were monitored in three time steps from the first half of the 19th century to date in the area of interest $24 \mathrm{~km} \times 6 \mathrm{~km}$. The extent of the area of interest was chosen with regard to the fact that a physical 3D model of the historic Vltava valley at a scale of 1: 6000 will be created for the same area. The physical model will show very clearly the extent of the extinct area caused by rising water levels after the construction of the dam.
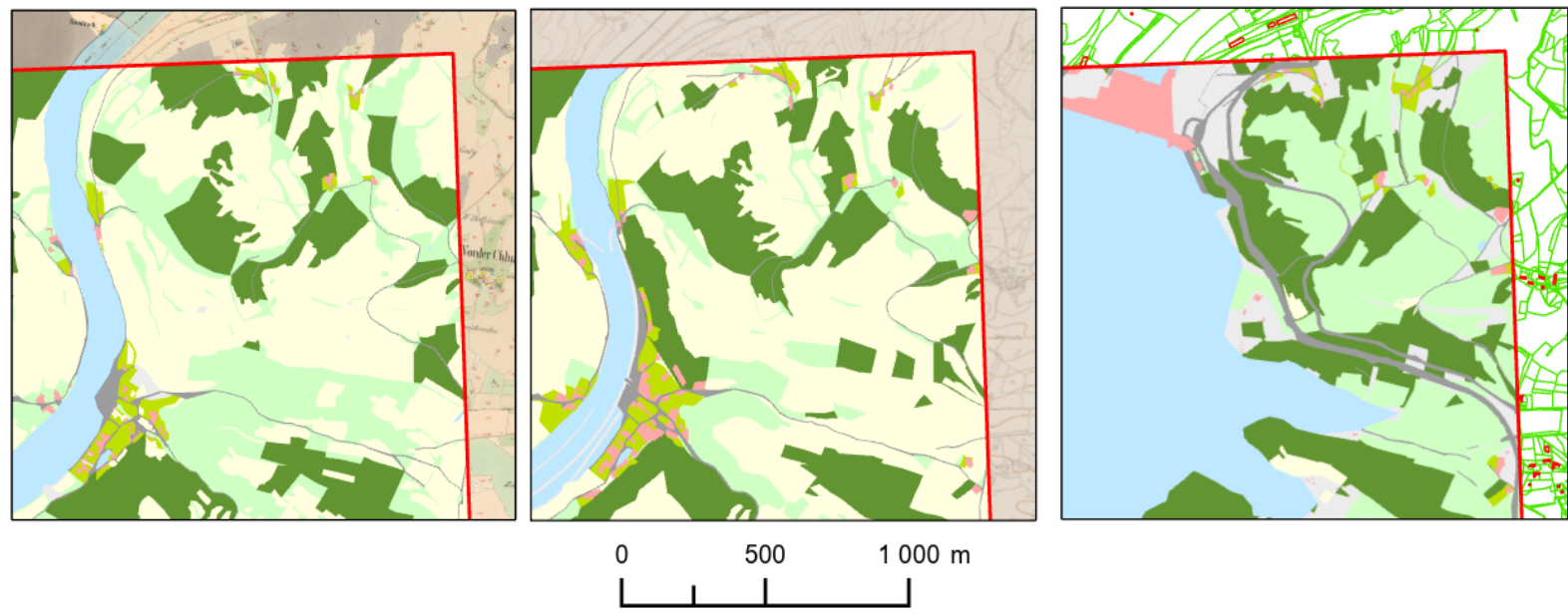

Figure 1. Time series of land cover maps and original maps for three different time steps (the left image - the first half of the 19th century, the middle image - the middle of the 20th century, the right image - year 2021).

The source of data for the historical land use/cover were old large-scale maps from two different time periods before the construction of the dam. The land use/cover from the first half of the 19th century was obtained from the imperial obligatory prints of maps of the stable cadastre of Habsburg Empire. These high aesthetically designed maps were made 
at a scale of 1: 2880 in the period 1824-1843. The land use in the area of interest in the middle of the 20th century (immediately before the construction of the dam) was taken over from the first edition of the State Map 1: 5000 derived. The scanned map sheets from both periods had to be first transformed into a uniform coordinate system, then a continuous mosaic of raster data covering the area of interest was created. Vectorization of land use was performed manually with the distinction of the following 8 land use/cover categories (arable land, permanent grassland, gardens and orchards, forest areas, water areas, roads, built-up areas, other areas).

As a basis for the current state of the landscape vector spatial data on parcels and buildings from the Register of Territorial Identification, Addresses and Real Estate (RÚIAN), which is one of the four basic registers of the Czech Republic, were used. Based on the type of land and information on the use of the land, the vector data were classified into 8 categories of land cover listed above.

Using spatial analyses and other GIS tools, vector data from three-time steps were compared and outputs were created in the form of tables, graphs and thematic maps, which are the content of the poster and which provide information on change and development of individual areas in the area of interest. Based on very detailed data at the level of individual parcels and buildings, we get detailed information about changes in individual categories of areas. In $29 \%$ of the area of interest, there was one land use/cover change during the entire monitored period, in $8 \%$ of the area land use/cover changed twice. Land use/cover changes in the area of interest partly correspond to the trends evident throughout the Czech Republic (loss of arable land, increase in built-up areas, other areas and roads). The influence of the water reservoir on the change of landscape is evident from the very significant increase of water areas between the second and third monitored period, and the related decrease of mainly forest areas, arable land and permanent grasslands.

\section{Acknowledgements}

This work was supported by the Grant Agency of the Czech Technical University in Prague, grant No. SGS21/054/OHK1/1T/11. 